\title{
La dimensión emocional del cuidado en la vejez: la mirada de los adultos mayores
}

\author{
The Emotional Dimension of Care in Old Age: The View of Older Adults \\ María Concepción Arroyo RuedA \\ Universidad Juárez del Estado de Durango, México \\ aguaconflores@hotmail.com \\ Luis Enrique SoTo Alanís \\ Universidad Juárez del Estado de Durango (UJED) \\ luisoto66@yahoo.com.mx
}

Recibido: 09/03/2013

Revisado: 08/04/2013

Aceptado: 04/06/2013

Disponible on line: 20/12/2013

\section{Resumen}

El presente trabajo de investigación muestra, la dimensión emocional de hombres y mujeres mayores que envejecen con enfermedad y dependencia, desde su propia perspectiva. Se trata de una investigación cualitativa realizada a adultos y adultas mayores que residen en la ciudad y municipio de Durango, México. Las técnicas de recolección de datos fueron la entrevista en profundidad y la observación participante, así como una ficha de identificación personal con datos sociodemográficos. Los resultados permiten identificar dos tipos de emociones: las de insatisfacción y las de gratificación. Desafortunadamente, las emociones insatisfactorias parecen dominar en la experiencia de vida de los participantes, pues es lo que predomina en el imaginario social y en los discursos que giran alrededor de esta etapa del ciclo vital. La interacción entre lo individual y lo social de la vejez y el envejecimiento crean un escenario emocional que determina las acciones en los adultos mayores. El trabajo social, a la par que otras disciplinas debe reflexionar desde una postura socio-política, su participación en el cambio de las percepciones e imágenes negativas de las personas mayores y promover una nueva cultura del envejecer.

Palabras clave: vejez, dependencia, cuidados, emociones.

\begin{abstract}
This study shows, from their own perspective, the emotional dimension of men and women aging with illness and dependency. This is a qualitative study with elderly men and women who live in the city and municipality of Durango, Mexico. The data collection techniques were in-depth interviews, participant observation and a personal identification card with socio-demographic data. The results allowed the identification of two types of emotions: dissatisfaction and gratification. Unfortunately, unsatisfactory emotions seem to dominate the life experience of the participants since it is what predominates in the social imagination and in the conversations revolving around this stage of the life cycle. The interaction between the individual and the societal aspects of old age and aging create an emotional stage that determines the actions of older adults. Social Work, together with other disciplines, should reflect from a socio-political stance their participation in changing the perceptions and the negative images of elderly people and promote a new culture of aging.
\end{abstract}

Keywords: aging, dependency, care, emotions.

Referencia normalizada: Arroyo Rueda, M. C., y Soto Alanís, L. E. (2013): «La dimensión emocional del cuidado en la vejez: la mirada de los adultos mayores». Cuadernos de Trabajo Social, 26(2): 337-347.

Sumario: Introducción. 1. Antecedentes. 2. Metodología. 3. Análisis y discusión de resultados. 4. Conclusiones e implicaciones para el Trabajo Social. 5. Referencias bibliográficas. 


\section{Introducción}

Cuidar, algo esencial e inherente en la vida de las personas, sigue siendo el núcleo de muchas relaciones humanas. En ese sentido, hablar de cuidados en la vejez, es referirse a una necesidad cotidiana de todas aquellas personas mayores con una edad avanzada que padecen alguna enfermedad o discapacidad. Dicha necesidad, aunque en diferentes grados, dimensiones y contextos se construye y se negocia socialmente (Cepal, 2009).

En la realidad actual, cuidar de las personas mayores representa una dificultad para muchas familias, sobre todo por las transformaciones sociales y culturales que se han dado en las últimas décadas: disminución de la fecundidad, cambio en el tamaño de los hogares, incorporación de las mujeres al mercado de trabajo, cambios en las percepciones y los valores de las familias. En este sentido, el cuidado ha tomado relevancia como tema de estudio en distintas disciplinas. Además, resultados de investigaciones recientes ubican este tema en el centro de un debate social y político (Robles, 2007; Arriagada, 2007; Aguirre, 2008; Cepal, 2009; Tobío, Agulló, Gómez y Martín, 2010).

Datos de importantes estudios sobre el cuidado se centran en el análisis de los efectos psicosociales y la salud física de quienes cuidan a adultos mayores enfermos y son abundantes (Aramburu, Izquierdo y Romo, 2001; Rivera, 2001; Deví y Ruiz, 2002; Aberg, Sidenvall, Hepworth, O'Reilly y Lithell, 2005). El principal aspecto que destacan alude a la «carga» para el cuidador, pues el impacto que tiene el cuidado en la salud mental y física de los cuidadores es una dimensión poco atendida por los programas institucionales. Sin embargo, poco se ha hablado de lo que sucede en el sujeto que recibe el cuidado, es decir, el adulto mayor. Es así como cobran interés las consecuencia emocionales, cuando no se cuenta con el apoyo de la familia para otorgar el cuidado; cuando los recursos materiales y económicos son escasos para hacer frente a la enfermedad; y cuando existen conflictos en la familia, o en la relación entre el adulto mayor y su cuidador.

En la experiencia del cuidado, los adultos mayores se insertan en una relación que produce un ambiente emocional difícil y estresante para él, para la familia y para el/la cuidador/a. La experiencia individual de cada uno de los participantes está inmersa en un vaivén emocional, que oscila de la tristeza a la esperanza y del enojo a la gratitud. En este escenario surge la intersubjetividad y toman peso importante las creencias, los prejuicios y las imágenes acerca de esa experiencia de vida. En la relación adulto mayor-cuidador se expresan emociones que crean y recrean realidades objetivas y significados personales. El presente trabajo se propone mostrar, con una mirada social y política, la dimensión emocional que surge en la experiencia de la vejez y la dependencia con la mirada de los/las adultos/as mayores.

\section{Antecedentes}

Existen escasos trabajos que tratan de la dimensión emocional en la relación de cuidadocuidador; es decir, del adulto mayor que recibe el cuidado y de la persona que se lo proporciona. Sin pretender ser exhaustivos, es importante en un primer momento darle significado a lo emocional, dimensión que ha sido estudiada con enfoques biológicos, psicológicos y sociales.

Perspectivas teóricas como la antropología, la fenomenología, las representaciones sociales o el constructivismo-construccionismo social, han abordado el tema de las emociones, generando análisis con diversas lógicas. En su artículo Antropología de las Emociones, Fernández (2011) hace una amplia compilación de definiciones de distintas disciplinas y enfoques. Rescatamos las más destacadas y ampliamos con otros autores que han abordado este importante tema.

En una óptica que enfatiza lo biológico: «las emociones suponen un complejo proceso hormonal, fisiológico e incluso molecular que sirve para establecer y asentar la vida en sociedad». Para la antropología, las emociones se entienden como el campo básico sobre el que se crea la red de conexiones y prácticas sociales que devienen sistemas y contenidos culturales. En esta disciplina, se consideran las emociones como la matriz sobre la que se mueve la vida social, los tipos básicos de conductas relacionales sobre las que se da la comunicación necesaria para crear los diversos mundos culturales (Fericgla, 2010). Los estudios sociales y humanistas requieren indiscutiblemente una «matriz emocional» para comprender el espíritu de una cultura. Es decir, la 
dinámica del proceso social es necesaria para comprender los procesos psicológicos que suceden en el interior del individuo (Fromm, 1979; citados en Fernández, 2011).

Uno de los campos de conocimiento que más ha estudiado este tema es la psicología. Para la perspectiva psicológica, «las emociones suponen el impulso básico de la mente consciente además de una fuente de patologías diversas si han sido mal socializadas»». No obstante, otra rama de la psicología - la psicología social o sociohistórica- destaca que lo emocional también forma parte de la realidad de los sujetos, por lo que la emoción es igualmente un proceso subjetivo que se asocia de múltiples formas con los procesos simbólicos (González, 2007). Por su parte, las psicologías cognitivas ponen el acento en la valoración. Lazarus $(1982,2000 \mathrm{a})$ presenta una hipótesis cognitivo-fenomenológica que busca la comprensión de la vivencia, de las decisiones y de las acciones de los seres humanos y sus procesos de elaboración de la información y la interrelación persona-medioambiente como entornos que se retroalimentan. Un enfoque socioconstruccionista (Hoschild, 2008) y antropológico de las emociones ha sido postulado por Gordon, Collins y Le Breton (citados en Fernández, 2011).

En la ética del cuidado, las emociones han sido motivo de análisis de Graham, Kittay, Ungerson, Fisher y Wood (citados en Vázquez y Enríquez, 2012). Las emociones, sentimientos o afectos, se caracterizan por creencias, juicios y deseos, cuyos contenidos no son naturales, sino determinados por sistemas de creencias y significados sociales vinculados a contextos particulares (Armon Jones, 1986; Lazarus, 2000a; Hochschild, 2008). Las aportaciones de Hochschild en este tema son muy importantes, puesto que conceptualiza la emoción como una conciencia de cooperación corporal con una idea, un pensamiento o una actitud, y a la etiqueta adosada a esa conciencia. Y por «sentimiento» alude a una emoción «más suave» ${ }^{1}$. Para Gordon los efectos estructurales sociales sobre el flujo de la emoción pasa al menos a través de tres procesos de interacción. En la di- ferenciación de la emoción, las sociedades y subgrupos distinguen en su idioma y el comportamiento social entre muchos tipos de una emoción (por ejemplo, formas de ira). A través de la socialización, los individuos aprenden a sentirse, atender, expresar y reconocer las emociones particulares identificadas en su sociedad. Finalmente, el manejo de los sentimientos es la regulación de ambas expresiones y sentimientos de acuerdo con las normas de adecuación. Estos tres procesos sociales vinculan la estructura social amplia con la experiencia emocional y el comportamiento de los individuos.

En una perspectiva construccionista, Hoschild expresa que las emociones son parte del intercambio social orientadas a la cognición y a la acción, y cuentan con creencias, normas y expresiones propias (Hoschild, 2008). Para Gergen, pionero del construccionismo social, las emociones no sólo tienen influencia en la vida social, sino que son la base de la vida social misma. Las emociones tienen un significado personal, pero no es posible desprenderlas de un significado cultural más amplio en el que se lleva a cabo una evaluación moral de la emoción. En este sentido, las emociones adquieren un significado relacional que varía de un contexto cultural a otro, pues el significado personal de lo que está sucediendo depende de la manera en que actúa la otra persona en la interacción (Gergen, 1996; Lazarus, 2000a).

Así mismo, Fabregat y Chodorow (citados en Fernández, 2011) enfatizan que:

La relación entre emociones y cultura es íntima e indisociable. Las emociones son las formas en que experimentamos el mundo y las respuestas emocionales reflejan la cultura, toda vez que son moldeadas por ella. Los seres humanos significan las imágenes y prácticas culturales, las crean y recrean a través de procesos relacionados con la biografía personal, con estrategias y prácticas intrapsíquicas e interpersonales en el marco cultural».

Gordon (1990), plantea que las emociones se constituyen como universos simbólicos subjetivos, producto de las interacciones entre las

${ }^{1}$ Si bien aclaramos que los conceptos: emoción y sentimiento tienen un significado de cierta manera diferente, en este trabajo utilizaremos de manera indistinta ambos términos, dado que en el contexto discursivo de nuestros participantes, los dos conceptos se usan como si tuvieran el mismo significado. 
personas y su contexto sociocultural. Para que una emoción surja es necesario una valoración previa de la situación emocional, y no es posible hacer una valoración sin estar envueltos en nuestro propios entendimientos sociales. Entender las respuestas emocionales y su origen implica comprender el contexto en el que surgen. Esto requiere conocer cómo se construyen las relaciones y lo que es importante o no para las personas. La forma en que las personas jerarquizan lo que es o no es relevante modela las reacciones emocionales lo que orienta la acción de los participantes (Lazarus, 2000a).

En el tema de la vejez, la enfermedad y la dependencia, la expresión emocional es inevitable, producto de la tensión entre los actores principales: adulto mayor y familiar cuidador. Las narrativas de las emociones y los sentimientos, como se ha dicho anteriormente, si bien se ubican en un marco subjetivo, se originan en lógicas de razonamiento social, de tal forma que reflejan también un marco de referencia objetivo, de orden cultural.

\section{Metodología}

Este trabajo forma parte de una investigación cualitativa más amplia en la que se exploraron las representaciones sociales de la vejez y el cuidado en 20 adultos mayores con enfermedades crónicas y dependencia física, en Durango (México). La muestra fue de tipo teórico y por conveniencia, delimitando el número de casos mediante el proceso de saturación (Glasser y Strauss, 1967; Flick, 2004; Martínez, 2006). Los casos fueron seleccionados en tres unidades del sector salud de la localidad, a través de informantes clave (médicos, enfermeras y trabajadores sociales) donde los participantes eran usuarios de distintos servicios médicos. Con el propósito de buscar un grupo heterogéneo, se realizaron entrevistas en profundidad a 10 varones y 11 mujeres mayores, con distintos niveles socioeconómicos: dos vivían en un área rural cercana a la ciudad; tres en la ciudad con familiares, pero provenientes de área rural, cuatro en colonias populares, cinco en fraccionamientos de interés social, y seis en la zona urbana cercana al centro de la ciudad). Menos de la mitad de los participantes perciben la pensión y la mayoría con escolaridad básica. La edad oscilaba entre los 70 y los 93 años y se buscó que fueran adultos mayores en condicio- nes mentales favorables a la entrevista; es decir, se procuró que su narrativa fuera coherente. Todos los participantes padecían una enfermedad crónica discapacitante. Entre los padecimientos más frecuentes estaban: asma, cáncer, cirrosis hepática, diabetes, nefropatías, enfermedades cardiovasculares y fracturas.

La metodología cualitativa permitió desde el inicio abordar el tema en un escenario «natural», pues todos los participantes fueron entrevistados en su hogar. Se planearon tantas entrevistas como fueron necesarias, a fin de lograr el criterio de saturación teórica; en total se realizaron 28 entrevistas. Se estableció un acuerdo verbal acerca de la confidencialidad de los datos, de tal forma que toda la información se proporcionó voluntariamente utilizando una grabadora y notas de observación. Para el análisis de los datos se utilizó el programa Etnograph para datos cualitativos. En el análisis se realizó una lectura profunda de los datos de las entrevistas con el propósito de rescatar la subjetividad de cada participante, y así obtener una mayor comprensión del fenómeno de estudio. Posteriormente se elaboró un listado y un mapa de códigos que integrados en categorías, posibilitaron la aparición de temas relevantes para el análisis (Bolívar y Fernández, 2001; Rodríguez, 2007).

\section{Análisis y discusión de resultados}

Los resultados que se presentan a continuación se refieren a las emociones del adulto mayor que surgen alrededor del cuidado en la vejez avanzada. Las narrativas de los entrevistados nacen en la interacción de la convivencia diaria entre ellos y sus cuidadores. La percepción de esta interacción emocional, desde la perspectiva de las personas mayores y el sentido y el significado que le asignaron, es lo que destacamos en los resultados.

Para ello, rescatamos la clasificación que hace Lazarus (2000a) de las emociones. Agrupamos las emociones identificadas en los adultos mayores en: emociones existenciales como la ansiedad, miedo, culpa y vergüenza; y las emociones provocadas por condiciones de vida desfavorables, como la esperanza, la tristeza y la depresión. En los relatos de los participantes aparecen también las denominadas emociones empáticas, como la gratitud y la compasión, (Lazarus, 2000a) como otra di- 
mensión que posibilita tener una visión distinta de la vejez: aquella que tiene aspectos positivos y que deja a un lado los estereotipos negativos. Además, algunas de las expresiones de emocionalidad en los sujetos participantes, constituyen también estrategias de enfrentamiento ante las dificultades y vicisitudes de la cuarta edad. De esta manera presentaremos, en primera instancia, aquellas emociones existenciales que resultaron más significativas en la medida que establecieron ciertos patrones en la diada cuidador-receptor de cuidado; es decir, entre el adulto mayor y quien lo cuida. En un segundo momento haremos alusión a las emociones empáticas.

\subsection{Emoción: ansiedad-miedo}

Una primera emoción identificada en las entrevistas fue la de ansiedad y miedo. La aparición de esta emoción se relaciona en buena medida por la experiencia de enfermedad y deterioro en sus funciones básicas de la vida diaria. Las personas entrevistadas se muestran ansiosas por tener que depender de los demás y temen que su discapacidad avance. A continuación se muestran narrativas que reflejan emociones de ansiedad-miedo en nuestros participantes.

\section{Narrativas de la emoción de ansiedad-miedo}

Pues desesperación, angustia, tristeza, ansiedad, etc. Fíjese, estar nomás sentado y acostado porque no puedo ni, estando yo en la cama acostado, no puedo levantarme ni para sentarme, no, me tienen que ayudar a sentarme y pues es mucha dificultad, si (Caso 2; Rigoberto, 76 años).

O bien, tenemos otro ejemplo con Rosa María:

Me da miedo que llegue la noche [...] y a veces me da miedo, miedo a lo que será de mi vida, a veces me da miedillo.

Investigadora: ¿a qué le tiene miedillo? A morirme sola.

Investigadora: pero aquí está su hija y sus nietos: [...] sí, pero ellos tienen que salir a trabajar, todos, y a veces estoy sola, ¿qué tal si es en ese rato? [se muere] (Caso 6; Rosa María, 86 años).

Si bien el temor a morir es un miedo que se comparte socialmente, en los relatos de los participantes, el miedo a la muerte surge con mayor peso, cuando sus condiciones físicas se tornan vulnerables, cuando tienen la certeza que el ciclo de vida está por concluir, entonces, en ese momento es cuando se necesita estar con alguien, compartir la emoción con otro.

El significado en la emoción de ansiedadmiedo se centra en nuestra seguridad personal, en nuestra identidad como individuos, así como en temas de vida o muerte. Entre los sinónimos de la ansiedad son: aprensión, inquietud, preocupación y desasosiego, y su trama argumental es una amenaza incierta. Si la emoción de la ansiedad es existencial, y por lo tanto simbólica e indefinida, habitualmente se experimenta la ansiedad como algo que se refiere a peligros reales que se avecinan (Lazarus, 2000b).

El significado personal subyacente a la amenaza es existencial, por cuanto trata de quiénes somos en el mundo, de nuestro futuro bienestar, de la vida y de la muerte. Dicho significado se construye socialmente a partir de cómo se enfrentan las personas a una determinada situación, y a partir de los objetivos y creencias personales sobre ellos mismos y sobre el mundo.

\subsection{Emoción: culpa}

La culpa es otra emoción que experimentan los adultos mayores cuando sienten que están obstaculizando la vida personal de quienes los cuidan. Al parecer sienten que no son merecedores del cuidado que se les otorga, o bien, cuando el propio cuidador hace algún comentario de lo difícil que le resulta cuidarlo.

\section{Narrativas de la emoción de culpa}

Me siento con ganas de morirme para no seguir dando guerra ya, dando molestia.

No, pues, yo digo nada más pedirle a Dios que me de licencia de valerme por mí misma pa' no cansar a la gente (Caso 1; María Dolores, 93 años).

A ver si me quieren [una residencia para ancianos], para dejar vivir a estos [dos hijos que la cuidan), que formen su vida, ya son diez años que no han vivido su vida (Caso 19: María Elena).

La trama argumental de la culpa es sentir que se ha transgredido un código moral que forma parte de los valores de las personas. Las personas que experimentan culpa, no necesa- 
riamente incurren en algo moralmente malo, sino en creer que lo han hecho. La emoción de la culpa se centra en el sentimiento subjetivo de culpabilidad (Lazarus, 2000b). En el caso de los ancianos, la culpa sobreviene porque perciben la supervivencia como algo injusto para los cuidadores, de manera implícita y a veces explícita creen que el cuidarlos es un «sacrificio» para aquellos.

\subsection{Emoción: vergüenza}

Simultáneamente con la culpa, se identifica el surgimiento de la vergüenza en nuestros adultos mayores con dependencia física. Los participantes sienten vergüenza por no ser autosuficientes, por tener que pedir ayuda para satisfacer la mayoría de sus necesidades.

\section{Narrativas de la emoción de vergüenza}

Querer uno [... ] poder, querer hacer las cosas $[\ldots]$ y $[\ldots]$ y que ya no poder alcanzar uno algo que necesita $[\ldots]$ nada $[\ldots]$ me da pena.

Otro relato: Cuando veo que ya anda muy cansada, sí me da vergüenza pedirle un apoyo, pero ella [la cuidadora] lo ve y lo hace. (Caso 5; Juan Lorenzo, 76 años).

Según Lazarus (2000b), muchas veces puede establecer una confusión entre la culpa y la vergüenza. Freud habló del origen tanto de la culpa como de la vergüenza como una sola entidad mental: el superego, que se desarrolla en el proceso de crecimiento (Roudinesco y Plon, 1976). Pero, en tanto los valores morales como los ideales personales están implicados, puede que estén funcionando dos voces separadas, con diferentes contenidos, experiencias y conductas.

Mientras se busca expiar la culpa, la vergüenza se trata de esconder. La trama argumental de esta emoción es no estar a la altura del ideal personal o del ego. Vivir en desacuerdo con el ideal personal es una manera de evitar la vergüenza; parece que el objetivo subyacente que funciona en la vergüenza es evitar la crítica, el rechazo o el abandono social (Lazarus, 2000b).

Es interesante ver cómo las personas que luchan contra la vergüenza prefieren «esconderse del mundo», ya sea mostrando una buena fachada, o bien evitando los contactos sociales. En los ancianos, más que en los cuidadores, es común el sentimiento de vergüenza, dado que el ideal de todo ser humano es conservar la autonomía, sobre todo en el auto-cuidado del cuerpo.

En otro grupo de emociones se encuentran las que provocan las condiciones de vida desfavorables, tales como: una enfermedad grave, el dolor y sufrimiento por una pérdida real o potencial de un ser querido o el estatus personal (Lazarus, 2000b). Entre las emociones de este grupo que se consideran vinculadas a nuestro tema de estudio son la esperanza, la tristeza y la depresión.

\subsection{Emoción: esperanza}

Otro importante resultado en la exploración de las emociones es el que se refiere a la esperanza y la fe. Los adultos mayores, aún cuando sus condiciones son de vulnerabilidad física y a veces aislamiento social por su enfermedad, mantienen el sentimiento de esperanza y fe en que las cosas pueden mejorar. Estos sentimientos tienen arraigo en sus creencias religiosas o espirituales que mantienen a lo largo de sus vidas.

\section{Narrativas de fe y esperanza}

No, porque mire, temor no lo tengo, mi confianza en Dios siempre ha sido y creo que él no me abandona, otra ilusión que tengo es volver a trabajar porque así aunque gane poco no importa pero estoy haciendo algo útil, esa es la ilusión que tengo (Caso 4; Roberto, 73 años).

Yo quiero ver si me componen de aquí [señala la columna] y tengo la seguridad y Dios nuestro Señor de que sí puedo caminar (Caso 7: Cosme, 72 años).

Hay veces que estoy enferma y le digo: [a Dios] Tú sabes cuándo me vas a recoger, sólo dame esa paciencia que necesito para seguir adelante. (Caso 6; Rosa María, 86 años).

Es importante comprender la esperanza, no solamente porque puede ser un apoyo para la vida sino porque permite sacar el mejor partido de una mala situación, de vivir con entusiasmo y dignidad a pesar de todo (Lazarus, 2000b). La esperanza es esencialmente un antídoto contra la desesperanza, y es a través de ella como pueden disminuir los pensamientos negativos y sombríos que provoca una condición vital desfavorable, cuyo resul- 
tado es incierto. El significado personal de la esperanza es que la persona cree que existe una posibilidad de que su situación mejore, y su trama argumental es temer lo peor, pero anhelar lo mejor.

De acuerdo con Lazarus (2000b), consideramos la esperanza como emoción, pues aunque se cataloga como estrategia de afrontamiento, raramente es fría o desligada. Las personas pueden tener esperanza aunque estén desilusionadas, pueden ser pesimistas en cuanto a las condiciones globales, pero nunca renunciar a la esperanza de que el ser humano pueda mejorar. En la tradición judeo-cristiana, la esperanza se ve como algo positivo, como una virtud que construye fortaleza.

En el caso de los ancianos, cuando la esperanza de vida es corta, a veces se aprecia una lucha entre la esperanza y la desesperanza, oscilan entre estos estados mentales; por un lado, sienten esperanza por el tiempo que les queda de vida, y por el otro, surge la desesperanza por un fin que sienten próximo y por lo poco que pueden hacer ya con su vida. El significado personal según Lazarus (2000b), que consideramos aplicable al caso de los ancianos, es que tienen esperanza cuando perciben que existe una posibilidad de que el resultado que se teme no sea tan malo y de que al final todo saldrá bien.

Junto a la esperanza, se encuentra muy ligado el sentimiento de fe, como una actitud que genera fortaleza, y se relaciona principalmente con los principios que establece la religión, cualquiera que sea, pero además con una inclinación hacia lo espiritual. Así, los aspectos de fe y esperanza basados en la religión y espiritualidad, como dice Vázquez (2003, p.189) se convierten en un bálsamo y soporte espiritual capaz de prodigar real o imaginariamente una sensación de seguridad y protección divina que calma, mitiga y sana el sufrimiento que causa la enfermedad, el paso de los años, e incluso, la propia muerte.

No obstante, en esta dimensión emocional surgió como contraparte la desesperanza, que tomó un lugar importante en los datos. Es por ello por lo que mostramos ejemplos de narrativas de esperanza-desesperanza, como una muestra de la ambivalencia y contradicción que conlleva la experiencia de la vejez, la dependencia y el cuidado.

\subsection{Emoción: desesperanza}

Como contraparte a los ejemplos anteriores, la desesperanza es otra emoción que se identificó en los participantes. Abundante literatura sobre vejez menciona que las personas mayores presentan sentimientos de desesperanza al sentir que se acercan al ocaso de sus vidas, sobre todo cuando en esta última etapa están presentes la enfermedad, la discapacidad y el deterioro, como es el caso de nuestros participantes.

\section{Narrativas de desesperanza}

No pues, a pesar mío, le digo a mi padre Dios - nada más con que estuviera bien-pero ya con los años ya no se puede (Caso 6; Rosa María: anciana 86 años).

Aquí nomás todo el día, y en este estado, en que ya... ya no, ni esperanza de decir algún día me compondré $[. .$.$] cada día y cada día es un$ paso a la muerte [...] ya nomás estoy viendo, por qué estoy aquí todavía, ya sin ninguna esperanza de decir: ¿algún día me levantaré de esta cama?, ¿volveré a caminar? (Caso 3: María Santos, 89 años).

\subsection{Tristeza y depresión}

De igual forma que el temor y la ansiedad, se ha documentado ampliamente que la tristeza y la depresión son de las emociones más frecuentes y propias de la vejez. La explicación que distintos autores dan para argumentarlo, es que los adultos mayores se sienten tristes a causa de las distintas pérdidas que se presentan al entrar en esta etapa, como son: la pérdida del trabajo a consecuencia de la edad de jubilación, con ello, las personas mayores van perdiendo las relaciones establecidas en el mismo.

Además, el permanecer mayor tiempo en casa ocasiona ciertas dificultades de adaptación, tanto por parte de la familia como del propio adulto mayor, aunándolo en ocasiones a la presencia de conflictos. Además de todo ello, cuando aparecen las pérdidas de ciertas funciones o cuando dejan de realizar tareas esenciales de la vida cotidiana, a causa de su padecimiento o discapacidad, es inevitable que surjan sentimientos de tristeza y se pueda presentar la depresión. De hecho, en los servicios de atención a la salud, el trastorno depresivo es uno de los más comunes en las consultas médicas. 


\section{Narrativas de tristeza-depresión}

Ya ahora ya me acostumbré, porque mire, a veces pues sí me da tristeza, y lloro yo sola sin que nadie me vea, pero al principio no, no me hacía yo a la idea, pero ya vi que fue como imposible, ya que gano [...] sentía tristeza de que ya no podía hacer yo lo que yo hacía, pero me fui acostumbrando (Caso 6; Rosa María, 86 años).

Moralmente pues hay veces, hay ratos en que me ataca la tristeza, porque recuerdo yo los momentos en que trabajaba yo, me sentía a gusto (Caso 10; Jorge, 77 años).

La tristeza muchas veces se confunde con la depresión, pero es la tristeza la que predomina cuando se sufre una pérdida importante. El significado personal de la tristeza por la pérdida puede variar de persona a persona. El tipo de pérdidas en la vejez van desde la pérdida de la salud, a la pérdida de los seres queridos o bien la pérdida de un estatus o posición social que otorga identidad (Lazarus. 2000b).

Generalmente, las personas que sufren una pérdida tardan un cierto tiempo en asimilarlo, en aceptar y adaptarse a su nueva situación. Según Lazarus, la diferencia entre resignación y aceptación es sutil. Cuando nos resignamos, reconocemos con renuencia o aflicción la pérdida; cuando la aceptamos, hemos llegado a un acuerdo con ella y ya no nos sentimos intensamente acongojados, aunque podemos sentirnos tristes de vez en cuando. En otros casos, cuando surge la depresión por las pérdidas, esta depresión es emocional, pero no una emoción concreta, más bien es una combinación de varias emociones como el enojo, ansiedad y culpabilidad.

Finalmente, integramos en este apartado a las emociones empáticas, aquellas que se relacionan en cierto modo con la capacidad de sentir empatía por los demás, como son la gratitud y la compasión. Aún y cuando no se ha indagado al respecto de este tipo de emociones, según Lazarus (2000b), éstas son importantes en la vida cotidiana de las personas, especialmente en situaciones de enfermedad y dependencia.

\subsection{Emoción: gratitud}

El sentir gratitud por quien nos cuida, es un valor de muchos seres humanos. De hecho, cuando los padres envejecen, muchos hijos e hijas demuestran la gratitud, devolviendo el cuidado que los padres les prodigaron de niños. En nuestro estudio, analizamos especialmente la emoción de gratitud de los adultos mayores hacia sus hijos cuidadores. La gratitud en ellos se expresa de manera más importante hacia la hija o el hijo por quien recibe el cuidado principal, pues sienten que sin el apoyo de esa persona no podrían sobrevivir, como lo vemos a continuación en las narrativas:

\section{Narrativas de la emoción de gratitud}

Y le he dado muchas gracias, muchas gracias a Paty [hija cuidadora] y a su esposo, que ellos me recogieron, porque gracias a Dios, le doy gracias a Dios, que aquí Paty me recogió y ella es la que me está atendiendo (Caso 1; María Dolores, 93 años).

Claro que sí, claro que sí me siento apoyado, me siento con mucha seguridad, que le doy gracias a Dios que la tengo [a su esposa] ¿Qué haría yo si me faltara? (Caso 5; Juan Lorenzo, 76 años).

En este sentido, la trama argumental de la gratitud es apreciar un regalo altruista. $\mathrm{La}$ gratitud se considera una emoción moderada que surge a partir de la ayuda material, de información o emocional (Lazarus, 2000b). La gratitud es una forma de apreciación de la persona que se siente agradecida por cosas adicionales y en la que hay un sentimiento de una «relación intensa y positiva con otra persona» (Hoschild, 2008, p.157).

El necesitar ayuda es para muchas personas un problema psicológico, especialmente en nuestra sociedad individualista. El no poder hacerse cargo de uno mismo o ser una carga para los demás, es doloroso y perjudicial para la persona. Cuando los donantes hacen exhibición de su generosidad, es probable que los receptores sientan que el otro está siendo condescendiente. A pesar de que a veces hay buenas intenciones, la manera en que se presta la ayuda puede ser torpe, herir y causar tensiones que la otra persona no entiende del todo.

\subsection{Emoción: compasión}

La compasión es un sentimiento común en los cuidadores de personas enfermas o discapacitadas. No obstante, en este caso analizamos esta emoción en los adultos mayores, pues en las 
vicisitudes de la dependencia y el cuidado, los entrevistados identifican la dedicación y el esfuerzo realizado por los cuidadores. En ocasiones quienes cuidan de ellos tienen que renunciar a ciertas actividades o a sus espacios de recreación para poder ofrecer cuidado a su familiar enfermo. Es en esta dinámica, que los receptores de cuidado también experimentan compasión por quien los cuida.

\section{Narrativas de la emoción de compasión}

\author{
Investigadora: ¿Quién de su familia lo cuida \\ más o lo cuida mejor? \\ Jorge: pues igual, nada más que de todos \\ modos a la «pobre vieja» [se refiere a su espo- \\ sa] pues le echan la carga encima [refiriéndose \\ a sus hijos], y yo junto con ellos (Caso 10; Jor- \\ ge, 77 años).
}

En el ejemplo anterior, la expresión «pobre vieja» se percibe una actitud compasiva de parte del adulto mayor hacia la esposa cuidadora, pues ésta además tiene la responsabilidad de atender a sus hijos varones, quienes si bien colaboran en algunas tareas de cuidado de sus padre, son escasas y esporádicas. Una mujer, entre dos hijos varones y un esposo dependiente, es una apuesta a reforzar el rol tradicional femenino y las repercusiones físicas y emocionales de las mujeres cuidadoras. Un ejemplo más lo vemos en el siguiente caso.

Investigadora: ¿quién de su familia se preocupa más por Usted?

Rosa María: no pues a «mi' ja» [se dirige a la cuidadora], le «puedo» [similar a le importo] de todas maneras, me ha ayudado mucho «mi' ja» [...] pobrecita (Caso 6; Rosa María, 86 años).

Nuevamente, el término «pobrecita» está presente en el relato de los participantes. Referirse de esa manera a una persona en nuestra cultura, nos remite a la compasión por ella, ya sea porque atraviesa alguna situación difícil o cierto tipo de sufrimiento. En este estudio, los adultos mayores son conscientes de las repercusiones que tiene en el cuidador.

El significado personal de la compasión es que comprendemos que otro ser humano, como nosotros, está sufriendo y merece ayuda. A la compasión se le identifica como un estado emocional unilateral que nosotros mismos ge- neramos y experimentamos. La trama argumental de la compasión es sentirse conmovido $y$ experimentar aflicción por el sufrimiento de otra persona y querer ayudar. Si las personas sufren innecesariamente nuestra idea de justicia es quebrantada. Un objetivo de la compasión es procurar que la persona se sienta segura y feliz. Otro objetivo es que haya la esperanza de que si algún día nosotros estamos en las mismas condiciones, alguien será compasivo con nosotros. No obstante, en los ancianos también surgen sentimientos de compasión por quien los cuida, como vemos en las narrativas a continuación.

Es decir, los individuos varían mucho en la forma de sentir la compasión. Como vemos, las emociones cumplen un papel relevante en la experiencia de la vejez y el deterioro de los ancianos como en los cuidadores. A través de ellas conocemos los pensamientos y creencias que se construyen en torno al tema de estudio, así como la oportunidad que ofrecen de hacer «catarsis» a las personas cuando el dolor, la angustia, el enojo y el sufrimiento es difícil de llevar a cuestas.

No obstante, en muchos casos, ciertas emociones se reprimen, ya sea porque «no es adecuado», al percibirlo como un síntoma de debilidad cuando hay que aparentar «ser fuerte» ante las circunstancias, o bien, porque no se quiere preocupar o angustiar a la persona enferma. Todas estas «reglas del sentimiento», algunas veces más que favorecer el bienestar de las personas, promueven mayores «cargas» emocionales que afectan la salud mental de los participantes (Hoschchild, 2008; Lazarus, 2000b).

El ocultamiento de las emociones en los participantes es una forma de «distanciarse» ante uno mismo y ante los demás, de una experiencia que casi siempre es angustiante. En casos extremos, no sólo puede suceder el «ocultar» la emoción, sino también negarla. A continuación, las narrativas nos ejemplifican lo anterior.

Rosa $\mathrm{M}^{\mathrm{a}}:(\ldots)$ de primero si... ande [lloraba], sólo que yo lo hacía a escondidas, que no se diera cuenta ella [la cuidadora], porque pues yo extrañaba mi casa... (Caso 6; Rosa $\mathrm{M}^{\mathrm{a}}, 86$ años).

$\mathrm{M}^{\mathrm{a}}$ Dolores: (...) intranquila... a veces se me va el sueño... pensando... pero no digo nada... para no preocuparlos... (Caso 1; $\mathrm{M}^{\mathrm{a}}$ Dolores, 93 años) 
Es evidente la dificultad que implica manifestar el malestar, los sentimientos y emociones que nos muestran frágiles ante circunstancias adversas, ¿será porque vivimos en una sociedad que nos ha enseñado que todo está bien? $\mathrm{O}$ ¿será porque no confiamos en que haya una respuesta satisfactoria a nuestro sufrimiento? También será que es preocupante dar preocupación a otros, sobre todo si son las personas a las que se quiere. A fin de cuentas pueden ser todas estas cosas juntas.

\section{Conclusiones e implicaciones para el Tra- bajo Social}

\subsection{Conclusiones}

- El explorar las emociones en los participantes fue una experiencia de aprendizaje no sólo intelectual sino también humano. Habernos aproximado a un escenario poco conocido de la vejez avanzada y al cuidado permitió identificar la importante conexión entre lo subjetivo y lo social. La valoración personal que cada persona mayor hace sobre su experiencia de vida, está envuelta en un entendimiento social del envejecimiento y la vejez en el que participamos todos.

- La perspectiva socio-construccionista de las emociones nos refleja que existe una relación entre éstas y la cultura. Las emociones, como parte del intercambio social están orientadas a generar acciones y cogniciones. Dichas acciones y pensamientos constituyen elementos fundamentales son congruentes con emociones negativas, como la culpa, la tristeza, la ansiedad, el miedo y la desesperanza.

- No obstante, los adultos mayores, como cualquier otro ser humano, siempre buscan compensar el sufrimiento. Los participantes de este estudio implementan alternativas para enfrentar la adversidad de sus vidas; ellos se aferran a emociones como la esperanza y la fe. Mediante estas emociones tan arraigadas en el contexto latino, las personas mayores encuen- tran un sostén emocional para continuar con sus vidas.

- Finalmente, otro aspecto relevante en los resultados, es que aún cuando las emociones de compasión y gratitud se describen como más frecuentes en los cuidadores (Davis, 2005); simultáneamente, las personas mayores también expresan este tipo de sentimiento hacia sus cuidadores. De esta forma, estas emociones positivas intentan equilibrar las emociones negativas que predominan.

\subsection{Aplicaciones para el Trabajo Social}

- Como trabajadores sociales, los resultados de esta investigación nos reorientan a tener una visión más amplia acerca de las experiencias de vida de las personas mayores, de la dependencia y de los cuidados. La mirada entonces habrá de ser más comprehensiva, a fin de tener en cuenta siempre el vínculo entre subjetividad y cultura, entre lo micro y lo macro de los procesos humanos que son objeto de nuestra intervención.

- Enfoques teóricos como el de representaciones sociales, el construccionismo social y la gerontología crítica, son campos de conocimiento que deben incorporarse al acervo del Trabajo Social, pues nos ofrecen herramientas para construir explicaciones alternativas de fenómenos sociales como la vejez y el envejecimiento.

- El abordaje de las emociones en esta experiencia de vida requiere de nuevas formas de intervención que cuestione los aprendizajes y los saberes acerca de la vejez, la dependencia y la obligación femenina del cuidado. Los nuevos abordajes deberán enfocarse en la resignificación de las creencias y los estereotipos negativos que se construyen alrededor de estos fenómenos sociales.

- Igualmente, será necesario un trabajo colaborativo en el que a partir del encuentro con otras disciplinas, el trabajo social contribuya desde lo teórico y lo metodológico, pero también desde lo ético, al diseño de nuevas propuestas de trabajo social con adultos mayores.

\section{Referencias bibliográficas}

Aberg, A. C., Sidenvall, B., Lithell, H., O'Reilly, K. y Hepworth, M. (2005). On loss of activity and independence, adaptation improves life satisfaction in old age - a qualitative study of patients' perceptions. Quality of Life Research, 14, 1111-1125. Doi 10.1007/s11136-004-2579-8.

Aguirre, R. (2008). El Futuro del cuidado. En Irma Arriagada (ed.), Futuro para las Familias y Desafios para las Políticas. Santiago de Chile: CEPAL Serie Seminarios y Conferencias. Recuperado de: www.eclac.org/dds/noticias/paginas/.../Sintesis_Reunion_Especialistas.pdf. 
Aramburu, I., Izquierdo, A. y Romo, I. (2001). Análisis comparativo de necesidades psicosociales de cuidadores informales de personas afectadas de alzheimer y ancianos con patología invalidante. Revista Multidisciplinar de Gerontología, 11(2), 64-71. Recuperado de: www.nexusediciones.com/pdf/gero2001_2/gi-11-2-002.pdf

Armon-Jones, C. (1986). The thesis of the constructionism. The Social Construction of Emotion. Oxford: Basil Blackwell.

Arriagada, I. (2007). Familias y políticas públicas en América Latina: Una historia de desencuentros. Santiago de Chile: CEPAL.

Bolívar, A., Domingo, J. y Fernández, M. (2001). La investigación biográfica-narrativa en educación. Madrid: La Muralla.

CEPAL. (2009). Impactos de la dinámica demográfica sobre las generaciones y los cuidados en el marco de la protección social. Santiago de Chile: CEPAL-ONU. Recuperado de: www.eclac.org/publicaciones/xml/1/41721/LCW353.pdf.

Davis, A. J. (2005). El cuidar y la ética del cuidar en el siglo XXI: qué sabemos y qué debemos cuestionar. Revista del Colegio Oficial de Enfermería de Barcelona. Recuperado de: www.coib.org/uploadsBO/.../ANNE\%20DAVIS\%20CASTELLà_DEF.P.

Deví, J. y Ruiz, I. (2002). Modelos de estrés y afrontamiento en el cuidador enfermo con demencia. Mult Gerontol, 12 (1), 31-37. Recuperado de: http://www.nexusediciones.com/pdf/gero2002_1/g-12-1-005.pdf.

Fernández, A. (junio, 2011). Antropología de las emociones y teoría de los sentimientos. Revista Versión Nueva Época, 26. Recuperado de: bidi.xoc.uam.mx/resumen_articulo.php?

Fericgla, J. M. (2002). Envejecer. Una antropología de la ancianidad. Barcelona: Ed. Herder.

Flick, U. (2004). Introducción a la Investigación Cualitativa. Madrid: Ed. Morata.

Gergen, K. (1996). Realidades y relaciones. Barcelona: Paidós.

Glasser, B. y Strauss, A. (1967). The Discovery of Grounded Theory. Strategies for Qualitative Research. Nueva York: Aldine de Gruyter.

Gordon, S. (1990). Social structural effects on emotions. Recuperado de Research agendas in the sociology of emotions. Recuperado de: books.google.com.

González, F. (2007). Investigación cualitativa y subjetividad. México: McGraw Hill.

Hochschild, A. (2008). La mercantilización de la vida íntima. Apuntes de la casa y el trabajo. Buenos Aires: Katz Editores.

Lazarus, R. (2000a). Estrés y emoción. Manejo e implicaciones en nuestra salud. Bilbao: Desclée de Brouwer.

Lazarus, R. (2000b). Pasión y Razón. La comprensión de nuestras emociones. Buenos Aires: Paidós.

Martínez, M. (2006). Ciencia y Arte en la Metodología Cualitativa. México: Ed. Trillas.

Rivera, J. (2001). Redes familiares en el cuidado del anciano con demencia. Madrid: Consejo Económico y Social y Comunidad de Madrid.

Robles, L. (2007). La invisibilidad del cuidado a los enfermos crónicos. Guadalajara: Editorial Universitaria.

Rodríguez, T. (2007). Sobre el estudio cualitativo de la estructura de las representaciones sociales. En T. Rodríguez Salazar y M.L. García Curiel, Representaciones Sociales. Teoría e Investigación. Guadalajara: Universidad de Guadalajara.

Roudinesco, E. y Plon, M. (1976). Diccionario de Psicoanálisis. México: Paidós.

Tobío, C., Agulló, M. S., Gómez, M. V. y Martín, M. T. (2010). El cuidado de las personas. Un reto para el siglo XXI. Colección de Estudios Sociales «La Caixa», 28. Recuperado de: obrasocial.lacaixa.es/.../pdf/Estudios_sociales/vol28_completo_es.pdf.

Vázquez, E. y Enríquez, R. (2012). Una aproximación sociocultural a las formas de regulación emocional en cuidadores familiares de enfermos crónicos en Guadalajara, Jalisco. Desacatos, $39,55-72$. 